\title{
Composição química, valores energéticos e aminoácidos digestíveis verdadeiros de farinhas de vísceras para aves
}

\author{
Cinthia Eyng ${ }^{1}$, Ricardo Vianna Nunes ${ }^{2}$, Horacio Santiago Rostagno ${ }^{3}$, Luiz Fernando Teixeira \\ Albino $^{3}$, Christiane Garcia Vilela Nunes ${ }^{4}$, Luís Daniel Giusti Bruno ${ }^{2}$ \\ 1 Pós-graduação em Zootecnia - UNIOESTE - Marechal Cândido Rondon, PR. \\ 2 Curso de Zootecnia - CCA - UNIOESTE - Marechal Cândido Rondon, PR. \\ ${ }^{3}$ Departamento de Zootecnia - UFV - Viçosa, MG. \\ ${ }^{4}$ UTFPR - UFV - Dois Vizinhos, PR.
}

RESUMO - Objetivou-se determinar a composição energética e aminoacídica, os coeficientes de metabolizabilidade da energia e a digestibilidade de farinhas de vísceras para aves. Utilizou-se o método da alimentação forçada com galos adultos cecectomizados. O delineamento experimental utilizado foi o inteiramente casualizado, com quatro farinhas de vísceras (três de aves e uma de suínos e um jejum), seis repetições e um galo por unidade experimental. Os valores de energia metabolizável aparente foram $2.878,3.179,3.005$ e 2.145 , os de energia metabolizável aparente corrigida para balanço de nitrogênio $\left(\right.$ EMA $\left._{\mathrm{n}}\right), 3.017,3.487,3.155$ e $2.414 \mathrm{kcal} / \mathrm{kg}$ de matéria natural; os de EMV, de 3.720, 4.016, 3.840 e $2.981 \mathrm{kcal} / \mathrm{kg}$ de matéria natural e os de energia metabolizável verdadeira corrigida para balanço de nitrogênio $\left(\mathrm{EMV}_{\mathrm{n}}\right)$, de $3.239,3.367,3.350$ e $2.372 \mathrm{kcal} / \mathrm{kg}$ de matéria natural. De acordo com os valores energéticos e de energia bruta (EB), os coeficientes de metabolizabilidade aparente foram 53,$65 ; 61,96 ; 60,20$ e 46,13; os de metabolizabilidade aparente corrigida, 56,22; 67,96; 63,22 e 51,91 ; os de metabolizabilidade verdadeira, 69,$33 ; 78,28 ; 76,94$ e 64,11 ; e os de metabolizabilidade verdadeira corrigida, 60,$36 ; 65,62 ; 67,12$ e 51,01 para as farinhas de vísceras de aves e de suínos. Os coeficientes médios de digestibilidade verdadeira dos aminoácidos essenciais e não-essenciais para as farinhas de vísceras de aves e de suínos são, respectivamente, 81,20 e 74,55; 75,73 e 67,$15 ; 88,45$ e 85,$20 ; 89,27$ e 84,35 .

Palavras-chave: aminoácidos digestíveis, coeficientes de metabolizabilidade, composição química, energia metabolizável, galos cecectomizados

\section{Chemical composition, energetic values and real digestible amino acid of different viscera meals for poultry}

\begin{abstract}
It was aimed to determine energetic and amino acidic composition, coefficients of metabolizity of energy and digestibility of viscera meal for poultry. The method of forced feeding with cecectomized adult cockerel was used. A completely randomized design was used, with 4 different viscera meals ( 3 of poultry, one from swine, and one in fast), six replications and one cecectomized cockerel per experimental unit. The apparent metabolizable energy values were the following: 2,$878 ; 3,179 ; 3,005$ and 2,145 ; the values of aparent metabolizable energy corrected for nitrogen balance were the following: 3,$017 ; 3,487 ; 3,155$; and $2,414 \mathrm{kcal} / \mathrm{kg}$ of natural matter, the values of aparent metabolizable energy corrected were: $3,720,4,016,3,840$ and $2,981 \mathrm{kcal} / \mathrm{kg}$ of natural matter and the values of aparent metabolizable energy corrected for nitrogen balance were $3,239,3,367,3,350$ and $2,372 \mathrm{kcal} / \mathrm{kg}$ of natural matter. According to energetic values and gross energy, the apparent metabolizable coefficients were $53.65 ; 61.96 ; 60.20$ and 46.13 ; for the correct apparent metabolizability they were $56.22 ; 67.96 ; 63.22$ and 51.91 ; for the real metabolizity they were $69.33 ; 78.28 ; 76.94$ and 64.1 ; and the values for corrected real metabolizability were $60.36 ; 65.62 ; 67.12$ and 51.01 , for poultry and swine viscera meal. The real digestibility average coefficients of essential and non essential amino acids for poultry and swine viscera meal are 81.20 and $74.55 ; 75.73$ and $67.15 ; 88.45$ and $85.20 ; 89.27$ and 84.35 , respectively.
\end{abstract}

Key Words: cecectomized cockerels, chemical composition, coefficients of metabolizability, digestible amino acid, metabolizable energy

\section{Introdução}

O aumento da quantidade de resíduos produzidos pelos abatedouros e a preocupação em explorar o potencial desses resíduos como fontes proteicas, prevenindo problemas ambientais e obtendo alternativas de custo reduzido, tem tornado a farinha de vísceras ingrediente promissor na alimentação animal.

Recebido em 10/9/2008 e aprovado em 23/4/2009.

Correspondências devem ser enviadas para: nunesrv@hotmail.com 
A farinha de vísceras é o produto resultante da cocção, prensagem e moagem de vísceras, muitas vezes com inclusão de cabeças e pés, e, no caso da farinha de vísceras de aves, não deve conter penas. A composição química, conteúdo mineral e a qualidade da proteína podem variar dependendo da fonte da matéria-prima, do tempo de estocagem dos materiais, do método, da temperatura e da pressão utilizada no processamento (Najafabadi et al., 2007).

De acordo com Tucci et al. (2003), a utilização de alimentos alternativos e subprodutos da indústria é interessante do ponto de vista econômico da produção animal. Entretanto, para a formulação de rações balanceadas, é fundamental conhecer o valor nutricional e energético dos alimentos.

Nascimento et al. (2005) afirmaram que o valor de energia metabolizável dos alimentos é o que melhor representa a quantidade de energia disponível para as aves. No entanto, segundo esses autores, é necessário estimar esse valor, principalmente, para os alimentos com composição química muito variável, como os subprodutos avícolas. Da mesma forma, D’Agostini et al. (2004) afirmaram que o desempenho das aves é influenciado diretamente pelo nível energético das dietas, pois a energia é um dos fatores limitantes do consumo e pode ser utilizada nos processos que envolvem a mantença e o potencial produtivo.

Nem todos os aminoácidos dos ingredientes da dieta são igualmente digeridos pelo animal (Garcia et al., 2007), por isso, é necessário determinar seus coeficientes de digestibilidade para que se conheça a quantidade realmente aproveitada pelos animais. Esses coeficientes permitem a melhor utilização dos alimentos em rações balanceadas para aves e a redução dos custos de produção, além de diminuir a eliminação de poluentes (Brumano et al., 2006).

Assim, objetivou-se com este trabalho determinar a composição química, os valores energéticos e seus coeficientes de metabolizabilidade, os coeficientes de digestibilidade e os valores de aminoácidos digestíveis verdadeiros de farinhas de vísceras para aves.

\section{Material e Métodos}

O experimento foi realizado no Setor de Avicultura do Departamento de Zootecnia (DZO) da Universidade Federal de Viçosa (UFV) utilizando-se o método de alimentação forçada, descrito por Sibbald (1976), com galos adultos cecectomizados, linhagem Leghorn. As cirurgias de cecectomia das aves foram realizadas no Setor de Avicultura do DZO/UFV, usando-se a técnica descrita por Pupa et al. (1998), por meio de laparotomia abdominal e anestesia local.
O delineamento experimental utilizado foi o inteiramente casualizado, com quatro farinhas de vísceras (três farinhas de vísceras de aves e uma farinha de vísceras de suínos), seis repetições e um galo por unidade experimental, totalizando 24 galos. Simultaneamente, foram mantidos seis galos em jejum para realizar as correções correspondentes às perdas metabólicas e endógenas.

Os galos foram alojados individualmente em gaiolas de metabolismo e submetidos a período de adaptação às gaiolas e à dilatação do papo. Após este período, foram mantidos em jejum por 24 horas para esvaziamento do trato gastrintestinal. Em seguida, por meio de funil-sonda via esôfago até o papo, foram forçados a ingerir $30 \mathrm{~g}$ do alimento-teste, fornecido em duas porções, às 8 e $17 \mathrm{~h}$, para evitar regurgitação do alimento fornecido.

O período de coleta das excretas foi de 60 horas, com início após o primeiro fornecimento do alimento-teste, em intervalos de 12 horas, para evitar a fermentação. As excretas foram acondicionadas em potes plásticos e congeladas e, ao final do período experimental, foram descongeladas, homogeneizadas e levadas para estufa de ventilação forçada a $50^{\circ} \mathrm{C}$ por 72 horas, para posteriores análises de matéria seca, nitrogênio e energia bruta, juntamente com as amostras dos alimentos, por meio das metodologias descritas por Silva \& Queiroz (2002).

Para determinação da composição química dos alimentos estudados, foram analisados os valores de matéria seca (MS), nitrogênio $(\mathrm{N})$, extrato etéreo (EE), energia bruta (EB), matéria mineral (MM), cálcio, fósforo, magnésio, potássio, sódio, ferro, cobre e manganês, de acordo com metodologia descrita por Silva \& Queiroz (2002). O valor do diâmetro geométrico médio também foi determinado segundo técnica descrita por Zanotto \& Bellaver(1996).

Os aminogramas dos alimentos e das excretas foram realizados por meio de cromatografia líquida de alta performance (HPLC), no Laboratório da Ajinomoto Ltda.

Com base nos resultados das análises, os valores de energia metabolizável aparente (EMA), aparente corrigida para o balanço de nitrogênio $\left(\mathrm{EMA}_{\mathrm{n}}\right)$, energia metabolizável verdadeira (EMV) e verdadeira corrigida para o balanço de nitrogênio $\left(\mathrm{EMV}_{\mathrm{n}}\right)$ foram determinados utilizando-se as equações propostas por Matterson et al. (1965). Com base nos valores de energia bruta e de energia metabolizável aparente e verdadeira dos alimentos, foram calculados os coeficientes de metabolizabilidade dos valores energéticos.

Conhecendo-se as quantidades de aminoácidos ingeridos e excretados, bem como a fração metabólica e endógena obtida com galos em jejum, foram determinados os coeficientes de digestibilidade verdadeira e o conteúdo 
digestível de aminoácido de cada alimento, por meio de equações propostas por Rostagno \& Featherston (1977).

Como procedimento estatístico, aplicou-se o teste de comparação de médias Student Newman-Keuls, a 5\% de probabilidade, entre os valores médios dos coeficientes de metabolizabilidade e entre os valores médios dos coeficientes de digestibilidade verdadeira dos aminoácidos, por meio do Sistema de Análises Estatísticas - SAEG (UFV, 1999).

\section{Resultados e Discussão}

A composição química das farinhas de vísceras (Tabela 1) apresentou variações, uma vez que alimentos de origem animal, na sua maioria, apresentam pouca padronização, em razão do processamento a que são submetidos e de sua composição (Gomes et al., 2007).

O conteúdo de energia bruta das farinhas de vísceras de aves foi semelhante aos descritos por Paula et al. (2002) e inferiores aos apresentados por Najafabadi et al. (2007), de 5.320 e $5.645 \mathrm{kcal} / \mathrm{kg}$, respectivamente. No entanto, para a farinha de víscera de suínos $(4.651 \mathrm{kcal} / \mathrm{kg})$, o resultado obtido foi superior ao relatado por Santos et al. (2005) (4.006 kcal/kg) e Rostagno et al. (2005) (4.189 kcal/kg).

Os níveis de energia bruta das farinhas de vísceras apresentaram correlação negativa com a matéria mineral e proteína bruta. Vieites et al. (2000), estudando farinhas de carne e ossos, encontraram a mesma correlação para matéria mineral. A farinha de vísceras de suínos apresentou alto conteúdo de matéria mineral, cálcio e fósforo e esses níveis podem contribuir com o baixo conteúdo de energia bruta (Nascimento et al., 2002).

O valor médio de $57,57 \%$ de PB da farinha de vísceras de aves é superior ao apresentado por Bellaver et al. (2001), de 57,14\%, porém inferior ao encontrado por Tucci et al.(2003), de $60,75 \%$. Também foi inferior ao descrito por Nengas et al. (1999), de 58,35\%. O teor de proteína bruta da farinha de víscera de suínos observado neste trabalho $(49,69 \%)$ foi inferior ao encontrado por Santos et al. (2005), de 53,2\%.

Os valores de extrato etéreo das farinhas foram inferiores aos citados na literatura (Najafabadi et al., 2007; Tucci et al., 2003; Paula et al., 2002) e o conteúdo de matéria mineral das farinhas de vísceras de aves e suínos estudadas variou de 12,56 a 22,50\%. D'Agostini et al. (2004), estudando a composição química e energética de alguns alimentos para aves, encontraram na farinha de víscera de aves 3,02\% para matéria mineral e Paula et al. (2002), um conteúdo de 7,14\%. Em farinhas de vísceras suínas, Nunes et al. (2006) encontraram conteúdo médio de 32,15\% de matéria mineral.

Observou-se correlação negativa entre os valores de matéria mineral e os valores de extrato etéreo e energia bruta. Os valores de proteína bruta e matéria mineral correlacionaram-se positivamente nas farinhas de vísceras de aves e negativamente na farinha de vísceras suínas. Najafabadi et al. (2007) observaram correlação semelhante para os valores de energia bruta e extrato etéreo, o que, segundo os autores, torna o conteúdo de matéria mineral bom indicador para predizer a composição química de farinhas de vísceras.

Os valores de cálcio e fósforo foram superiores aos encontrados por D'Agostini et al. (2004). Contudo, Bellaver et al. (2001) obtiveram valores de 4,69\% e 2,61\% para cálcio e fósforo, respectivamente. Nunes et al. (2006), avaliando alimentos de origem animal para aves, observaram para a farinha de vísceras suínas, valor de fósforo $4,8 \%$ superior e de cálcio, $6,7 \%$ inferior. Valores superiores foram observados neste trabalho para cálcio, fósforo, cobre e

Tabela 1 - Composição proximal, valores de energia bruta e diâmetro geométrico médio de farinhas de vísceras de aves, expressos em matéria natural

\begin{tabular}{|c|c|c|c|c|}
\hline Composição nutricional & Farinha vísceras aves 1 & Farinha vísceras aves 2 & Farinha vísceras aves 3 & Farinha vísceras suínos \\
\hline Matéria seca $(\%)$ & 93,56 & 93,96 & 94,01 & 94,16 \\
\hline Proteína bruta $(\%)$ & 55,95 & 57,30 & 59,45 & 49,69 \\
\hline Extrato etéreo (\%) & 18,63 & 13,32 & 13,15 & 15,15 \\
\hline Diâmetro geométrico médio $(\mu \mathrm{m})$ & $1.076,68$ & 725,27 & 827,37 & $1.170,07$ \\
\hline Energia bruta $(\mathrm{kcal} / \mathrm{kg})$ & 5.365 & 5.131 & 4.991 & 4.651 \\
\hline Cinzas $(\%)$ & 12,56 & 17,33 & 17,53 & 22,50 \\
\hline Fósforo $(\%)$ & 2,01 & 2,91 & 1,73 & 3,19 \\
\hline Cálcio $(\%)$ & 3,10 & 5,11 & 4,71 & 4,13 \\
\hline Magnésio (\%) & 0,06 & 0,03 & 0,04 & 0,08 \\
\hline Potássio (\%) & 0,40 & 0,48 & 0,50 & 0,30 \\
\hline Sódio (\%) & 0,30 & 0,34 & 0,34 & 0,27 \\
\hline Ferro (ppm) & 103,13 & 83,91 & 58,77 & 79,71 \\
\hline Cobre (ppm) & 29,00 & 8,46 & 8,91 & 62,73 \\
\hline Manganês (ppm) & 12,36 & 5,60 & 5,02 & 20,27 \\
\hline Zinco $(\mathrm{ppm})$ & 145,86 & 153,00 & 167,86 & 218,82 \\
\hline
\end{tabular}


zinco e inferiores para manganês, potássio, sódio, ferro e magnésio em comparação aos citados no National Research Council - NRC (1994).

O diâmetro geométrico médio teve variação de 725,27 a 1.170,07 $\mu \mathrm{m}$. Segundo Zanotto \& Bellaver (1996), os alimentos são de granulometria fina quando apresentam diâmetro geométrico médio inferior a $0,60 \mathrm{~mm}$, média quando o diâmetro é de 0,60 a 2,00 mm e grossa quando o diâmetro é superior a 2,00 mm. Segundo essa classificação, tanto as farinhas de vísceras de aves quanto a farinha de vísceras suínas são de granulometria média.

Os valores de energia metabolizável aparente variaram de 2.145 a $3.179 \mathrm{kcal} / \mathrm{kg}$ entre as farinhas estudadas e os de energia metabolizável aparente corrigida para balanço de nitrogênio (Tabela 2), de 2.414 a $3.487 \mathrm{kcal} / \mathrm{kg}$. Os níveis de EMA $_{\mathrm{n}}$ foram $7,17 \%$ superiores aos de energia metabolizável aparente, fato decorrente do balanço de nitrogênio negativo das aves. Segundo Leeson \& Summers (2001), quando as aves estão em balanço negativo, o fator de correção é subtraído da energia da excreta e isso afeta o nível energético do alimento.

Os valores obtidos para energia metabolizável aparente das farinhas de vísceras de aves foram semelhantes ao conteúdo energético observado por Robbins \& Firman (2006) e Nascimento et al. (2002) em experimentos realizados com o mesmo método adotado neste trabalho.

Os níveis de energia metabolizável verdadeira foram de 2.981 a $4.016 \mathrm{kcal} / \mathrm{kg}$ e os de energia metabolizável verdadeira corrigida para o balanço de nitrogênio $\left(\mathrm{EMV}_{\mathrm{n}}\right)$, 2.372 a $3.367 \mathrm{kcal} / \mathrm{kg}$. Os valores de $\mathrm{EMV}_{\mathrm{n}}$ encontrados neste trabalho para a farinha de vísceras de aves foram semelhantes aos citados por Nascimento et al. (2002), enquanto os da farinha de vísceras de suínos foram inferiores. Os valores de energia metabolizável aparente e aparente corrigida pelo balanço de nitrogênio observado neste trabalho foram inferiores aos observados por Mello et al. (2009), que, entretanto, utilizaram o método de coleta total de excretas com alimentação a vontade.

A energia metabolizável dos subprodutos avícolas pode ser afetada por diversos fatores, entre eles, o tipo de processamento adotado pela indústria, a idade das aves e os níveis de inclusão do ingrediente na dieta. Segundo
Nunes et al. (2005), o conteúdo de PB e EE e a composição dos ácidos graxos e minerais provavelmente são os fatores que mais contribuem para as variações nos valores energéticos dos alimentos.

Os valores de energia metabolizável verdadeira foram 23,01\% maiores que os de energia metabolizável aparente e essa diferença pode estar relacionada à maior influência das perdas energéticas metabólicas e endógenas, decorrentes do baixo consumo de alimento (Nascimento et al., 2002). Entretanto, segundo Lesson \& Summers (2001), a energia metabolizável verdadeira não é afetada pelo consumo de alimento, ao passo que a energia metabolizável aparente reduz quando o consumo é baixo, pois as perdas energéticas metabólicas fecais e urinárias endógenas assumem grande porção da energia da excreta.

Os coeficientes de metabolizabilidade (Tabela 3) apresentaram diferença e foram menores $(\mathrm{P}<0,05)$ na farinha de vísceras de suínos. As diferenças nos coeficientes de metabolizabilidade entre as farinhas de vísceras podem ser explicadas pelo diâmetro geométrico médio, pois a exposição dos alimentos às ações das secreções digestivas e a taxa de passagem no trato grastrointestinal podem afetar o conteúdo energético do ingrediente. A farinha que apresentou maior diâmetro médio foi a de suínos, consequentemente, seus coeficientes de metabolizabilidade foram mais baixos, provavelmente pelo fato de que, quanto maior o tamanho de partícula, menor a superfície relativa de contato. De acordo com Brugalli et al. (1999), o tempo de passagem do bolo alimentar pelo trato gastrintestinal das aves é curto, portanto, a redução do tamanho de partículas contribui significativamente para melhorar a digestão e absorção dos nutrientes.

O conteúdo de matéria mineral, cálcio e fósforo nos ingredientes também pode interferir nos valores energéticos dos alimentos. Brugalli et al. (1999) atribuíram a redução nos valores energéticos ao excesso de íons cálcio e sódio e matéria mineral, que ocasiona saponificação das gorduras presentes na farinha de carne e ossos, reduzindo sua utilização pelas aves. Da mesma forma, Nunes et al. (2005) propuseram efeito semelhante com o resíduo de incubatório, uma vez que os níveis de matéria mineral e cálcio nesse alimento são elevados.

Tabela 2 - Valores energéticos das farinhas de vísceras de aves e suínos e seus respectivos desvios-padrão, expresso com base na matéria natural

\begin{tabular}{|c|c|c|c|c|}
\hline Energia metabolizável (kcal/kg) & Farinha vísceras aves 1 & Farinha vísceras aves 2 & Farinha vísceras aves 3 & Farinha vísceras suínos \\
\hline Aparente (EMA) & $2.878 \pm 194,28$ & $3.179 \pm 159,51$ & $3.005 \pm 178,87$ & $2.145 \pm 171,43$ \\
\hline Aparente corrigida $\left(\mathrm{EMA}_{\mathrm{n}}\right)$ & $3.017 \pm 194,98$ & $3.487 \pm 210,89$ & $3.155 \pm 97,33$ & $2.414 \pm 145,64$ \\
\hline Verdadeira (EMV) & $3.720 \pm 194,25$ & $4.016 \pm 159,51$ & $3.840 \pm 178,87$ & $2.981 \pm 171,43$ \\
\hline Verdadeira corrigida $\left(\mathrm{EMV}_{\mathrm{n}}\right)$ & $3.239 \pm 209,51$ & $3.367 \pm 228,59$ & $3.350 \pm 264,49$ & $2.372 \pm 257,44$ \\
\hline
\end{tabular}


Tabela 3 - Coeficientes de metabolizabilidade da energia bruta das farinhas de vísceras de aves e suínos

\begin{tabular}{|c|c|c|c|c|c|}
\hline $\begin{array}{l}\text { Coeficiente de } \\
\text { metabolizabilidade }(\%)\end{array}$ & $\begin{array}{c}\text { Farinha vísceras } \\
\text { aves } 1\end{array}$ & $\begin{array}{c}\text { Farinha vísceras } \\
\text { aves } 2\end{array}$ & $\begin{array}{c}\text { Farinha vísceras } \\
\text { aves } 3\end{array}$ & $\begin{array}{c}\text { Farinha vísceras } \\
\text { suínos }\end{array}$ & CV $(\%)$ \\
\hline Aparente & $53,65 \mathrm{~b} \pm 3,62$ & $61,96 \mathrm{a} \pm 3,11$ & $60,20 \mathrm{a} \pm 3,58$ & $46,13 \mathrm{c} \pm 3,69$ & 6,321 \\
\hline Verdadeira & $69,33 b \pm 3,62$ & $78,28 \mathrm{a} \pm 3,11$ & $76,94 a \pm 3,58$ & $64,11 \mathrm{c} \pm 3,68$ & 4,860 \\
\hline Verdadeira corrigida & $60,36 \mathrm{a} \pm 3,91$ & $65,62 \mathrm{a} \pm 4,45$ & $67,12 \mathrm{a} \pm 5,30$ & $51,01 b \pm 5,53$ & 7,936 \\
\hline
\end{tabular}

Médias, na linha, seguidas de letras distintas diferem $(\mathrm{P}<0,05)$ pelo teste Student Newman-Keuls.

Além desses fatores, a composição dos ácidos graxos das farinhas pode influenciar os valores de coeficientes de metabolizabilidade. Geralmente, os ácidos graxos insaturados são mais eficientemente digeridos que os saturados, entretanto a relação insaturado:saturado de 4:1 parece ser a proporção ideal para que ocorra sinergismo entre os ácidos graxos. Além disso, a composição de ácidos graxos e seu posicionamento no triglicerídeo podem influenciar os valores energéticos.

Os coeficientes de metabolizabilidade da energia encontrados para as farinhas de vísceras estudadas foram mais baixos para a farinha de vísceras de suínos, em decorrência da maior proporção de ácidos graxos saturados no produto das vísceras de suínos.

Entre as amostras estudadas, as farinhas de vísceras de aves $1 \mathrm{e} 2$ foram as que apresentaram o menores coeficientes de digestibilidade dos aminoácidos (Tabelas 4 e 5). Os coeficientes de digestibilidade de histidina $(80,2)$, valina $(80,3)$, isoleucina $(83,9)$, leucina $(85,4)$ e fenilalanina $(86,4)$ foram semelhantes aos citados por Garcia et al. (2007).
Entretanto, Brumano et al. (2006) encontraram valores mais baixos para a maioria dos aminoácidos, exceto treonina, valina e isoleucina. Valor inferior foi reportado por Parsons (1996) para lisina $(75,0)$ na farinha de vísceras de aves e por Dalibard \& Paillard (1995) para lisina $(71,0)$ e metionina $(68,0)$.

As diferenças entre os coeficientes de digestibilidades dos aminoácidos, além de serem influenciadas pela composição da matéria-prima utilizada, podem ainda ser decorrentes do processamento térmico ao qual as farinhas de vísceras são submetidas (Pozza et al., 2005). Segundo Nascimento (2000), em caso de processamento excessivo, pode-se ter produto com baixo teor proteico, em decorrência das perdas dos aminoácidos sulfurados (cistina é transformada em lantionina). No entanto, numa situação de processamento insuficiente, a hidrólise pode ocorrer de forma incompleta, fazendo que os valores de digestibilidade dos nutrientes seja menor. De acordo com Leeson \& Summers (2001), a redução na digestibilidade da lisina pode ser atribuída à formação dos produtos da reação de Maillard durante o processamento térmico.

Tabela 4 - Coeficientes de digestibilidade verdadeira dos aminoácidos de farinhas de vísceras de aves e suínos

\begin{tabular}{|c|c|c|c|c|c|}
\hline $\begin{array}{l}\text { Aminoácido } \\
\text { essencial (\%) }\end{array}$ & $\begin{array}{c}\text { Farinha vísceras } \\
\text { aves } 1\end{array}$ & $\begin{array}{c}\text { Farinha vísceras } \\
\text { aves } 2\end{array}$ & $\begin{array}{c}\text { Farinha vísceras } \\
\text { aves } 3\end{array}$ & $\begin{array}{c}\text { Farinha vísceras } \\
\text { suínos }\end{array}$ & CV (\%) \\
\hline Lisina & $82,89 b \pm 1,06$ & $77,59 \mathrm{c} \pm 3,15$ & $90,93 a \pm 1,99$ & $90,75 \mathrm{a} \pm 1,54$ & 2,44 \\
\hline Metionina & $84,91 b \pm 0,86$ & $79,33 \mathrm{c} \pm 2,53$ & $91,81 \mathrm{a} \pm 1,30$ & $91,91 \mathrm{a} \pm 1,50$ & 1,91 \\
\hline Met + Cis & $74,61 b \pm 1,46$ & $68,15 \mathrm{c} \pm 4,34$ & $87,22 \mathrm{a} \pm 2,59$ & $86,57 \mathrm{a} \pm 2,37$ & 3,65 \\
\hline Treonina & $73,08 b \pm 1,96$ & $66,41 \mathrm{c} \pm 4,65$ & $81,73 a \pm 4,02$ & $84,34 a \pm 2,85$ & 4,62 \\
\hline Arginina & $91,11 b \pm 2,26$ & $84,75 c \pm 2,04$ & $94,68 \mathrm{a} \pm 1,55$ & $94,78 \mathrm{a} \pm 0,86$ & 1,93 \\
\hline Histidina & $76,78 b \pm 2,78$ & $70,56 \mathrm{c} \pm 3,92$ & $88,52 \mathrm{a} \pm 2,11$ & $87,53 \mathrm{a} \pm 2,17$ & 3,51 \\
\hline Valina & $79,13 b \pm 1,49$ & $73,96 \mathrm{c} \pm 4,29$ & $84,82 \mathrm{a} \pm 3,29$ & $86,28 \mathrm{a} \pm 2,83$ & 3,87 \\
\hline Isoleucina & $80,47 b \pm 1,18$ & $75,12 \mathrm{c} \pm 3,84$ & $85,68 \mathrm{a} \pm 4,97$ & $88,94 a \pm 2,08$ & 4,07 \\
\hline Leucina & $83,86 b \pm 1,04$ & $79,70 \mathrm{c} \pm 3,33$ & $89,29 a \pm 3,02$ & $90,54 a \pm 1,76$ & 2,88 \\
\hline Fenilalanina & $85,15 b \pm 1,21$ & $81,74 c \pm 3,16$ & $89,86 a \pm 3,12$ & $91,09 a \pm 1,55$ & 2,79 \\
\hline Média & 81,20 & 75,73 & 88,45 & 89,27 & \\
\hline \multicolumn{6}{|c|}{ Aminoácido não-essencial } \\
\hline Cistina & $58,14 b \pm 2,34$ & $46,09 \mathrm{c} \pm 8,05$ & $80,28 \mathrm{a} \pm 7,14$ & $76,95 \mathrm{a} \pm 4,84$ & 9,20 \\
\hline Alanina & $82,58 b \pm 0,98$ & $76,17 \mathrm{c} \pm 4,15$ & $85,90 a \pm 2,71$ & $87,13 a \pm 2,21$ & 3,32 \\
\hline Ácido aspártico & $62,37 b \pm 1,81$ & $56,24 \mathrm{c} \pm 5,39$ & $80,32 \mathrm{a} \pm 5,30$ & $77,28 \mathrm{a} \pm 3,12$ & 6,07 \\
\hline Ácido glutâmico & $81,02 b \pm 1,47$ & $73,82 \mathrm{c} \pm 3,13$ & $88,76 a \pm 2,59$ & $87,68 \mathrm{a} \pm 1,85$ & 2,84 \\
\hline Serina & $75,62 b \pm 1,72$ & $69,65 \mathrm{c} \pm 4,03$ & $82,71 \mathrm{a} \pm 3,57$ & $85,12 \mathrm{a} \pm 2,63$ & 3,98 \\
\hline Tirosina & $87,58 b \pm 1,56$ & $80,92 \mathrm{c} \pm 4,96$ & $93,22 \mathrm{a} \pm 1,24$ & $91,95 \mathrm{a} \pm 1,44$ & 3,13 \\
\hline Média & 74,55 & 67,15 & 85,20 & 84,35 & \\
\hline
\end{tabular}

Médias, na linha, seguidas de letras distintas diferem $(\mathrm{P}<0,05)$ pelo teste Student Newman-Keuls. 
Esses produtos são resistentes à hidrólise pelas enzimas endógenas digestivas.

Reações entre os grupos carboxil dos ácidos aspártico e glutâmico e o grupamento $\alpha$-amino da lisina também podem ser produzidas durante o processamento térmico. $\mathrm{O}$ produto resultante dessas reações possui ligações que podem ser resistentes à hidrólise enzimática. A ocorrência dessas reações pode prejudicar a digestibilidade subsequente dos aminoácidos (Leeson \& Summers, 2001), o que pode ter ocorrido com a farinha de vísceras de aves 2 , que apresentou reduzida digestibilidade, tanto da lisina quanto do ácido aspártico e o ácido glutâmico.

Os resultados encontrados neste trabalho para aminoácidos não-essenciais (Tabela 5) foram inferiores aos obtidos por Garcia et al. (2007). Dalibard \& Paillard (1995) encontraram menor valor de cistina, no entanto, Brumano et al. (2006) observaram valores superiores para alanina, ácido aspártico e ácido glutâmico.

O tratamento térmico excessivo da farinha pode originar perdas de aminoácidos sulfurados, como citado anteriormente, por meio da transformação da cistina em lantionina, por exemplo, e reduz o valor proteico da farinha. Isso pode ter ocorrido com a farinha de vísceras de aves 2 , que apresentou o menor valor de digestibilidade desse aminoácido, que pode estar relacionado à alta temperatura utilizada na fabricação da farinha.

As digestibilidades médias dos aminoácidos essenciais foram mais altas que a dos não-essenciais, o que pode indicar mecanismo do organismo para melhor o aproveitamento dos aminoácidos nutricionalmente indispensáveis (Ost et al., 2007). A farinha de víscera de aves 2 apresentou menor composição aminoacídica, o que pode ser atribuído ao alto conteúdo de matéria mineral. Shirley \& Parsons (2001) estudaram o efeito do conteúdo mineral sobre a qualidade proteica da farinha de carne e ossos e observaram correlação negativa sobre a concentração de todos os aminoácidos essenciais, exceto arginina, no entanto, não observaram efeitos negativos sobre a digestibilidade desses aminoácidos.

O aminoácido encontrado em maior quantidade entre os essenciais e não-essenciais das amostras de farinhas de vísceras foi o ácido glutâmico, constatação também realizada por Pozza et al. (2005) em farinhas de vísceras.

Da mesma forma que foi observada diferença no conteúdo total de aminoácidos das farinhas de vísceras estudadas, houve variabilidade entre os valores de aminoácidos digestíveis observados neste trabalho e os documentados por Brumano et al. (2006) e Garcia et al. (2007). Essa variação pode estar associada à oscilação de valores no conteúdo aminoacídico total e/ou nos coeficientes de digestibilidade dos aminoácidos, que pode resultar em diferenças nos valores de aminoácidos digestíveis (Ost et al., 2007).

Devido à grande diversidade de resultados da composição proteica e aminoacídica dos produtos, principalmente os de origem animal, as formulações devem ser baseadas em aminoácidos digestíveis. Desta forma, atenderão melhor as exigências nutricionais das aves que quando formuladas com base nas concentrações totais de aminoácidos (Lemme et al., 2004).

Tabela 5 - Valores de aminoácidos totais e aminoácidos digestíveis verdadeiros dos alimentos, em porcentagem da matéria natural

\begin{tabular}{|c|c|c|c|c|c|c|c|c|}
\hline \multirow[t]{2}{*}{ Aminoácido } & \multicolumn{2}{|c|}{ Farinha vísceras aves 1} & \multicolumn{2}{|c|}{ Farinha vísceras aves 2} & \multicolumn{2}{|c|}{ Farinha vísceras aves 3} & \multicolumn{2}{|c|}{ Farinha vísceras suínos } \\
\hline & $\begin{array}{c}\text { Aminoácidos } \\
\text { totais }\end{array}$ & $\begin{array}{c}\text { Aminoácidos } \\
\text { digestíveis }\end{array}$ & $\begin{array}{c}\text { Aminoácidos } \\
\text { totais }\end{array}$ & $\begin{array}{c}\text { Aminoácidos } \\
\text { digestíveis }\end{array}$ & $\begin{array}{c}\text { Aminoácidos } \\
\text { totais }\end{array}$ & $\begin{array}{c}\text { Aminoácidos } \\
\text { digestíveis }\end{array}$ & $\begin{array}{c}\text { Aminoácidos } \\
\text { totais }\end{array}$ & $\begin{array}{c}\text { Aminoácidos } \\
\text { digestíveis }\end{array}$ \\
\hline Lisina & 2,96 & 2,45 & 2,53 & 1,96 & 3,44 & 3,13 & 3,40 & 3,09 \\
\hline Metionina & 0,90 & 0,76 & 0,73 & 0,58 & 1,12 & 1,03 & 1,10 & 1,01 \\
\hline Metionina + cistina & 1,44 & 1,07 & 1,10 & 0,75 & 1,75 & 1,53 & 1,71 & 1,48 \\
\hline Treonina & 2,00 & 1,46 & 1,67 & 1,11 & 2,18 & 1,78 & 2,11 & 1,78 \\
\hline Histidina & 0,93 & 0,71 & 0,87 & 0,61 & 1,12 & 0,99 & 1,11 & 0,97 \\
\hline Valina & 2,38 & 1,88 & 2,06 & 1,52 & 2,66 & 2,24 & 2,61 & 2,25 \\
\hline Isoleucina & 1,69 & 1,36 & 1,32 & 0,99 & 2,05 & 1,76 & 2,06 & 1,83 \\
\hline Leucina & 3,43 & 2,88 & 2,91 & 2,32 & 3,76 & 3,36 & 3,73 & 3,38 \\
\hline Fenilalanina & 1,90 & 1,62 & 1,65 & 1,35 & 2,13 & 1,91 & 2,13 & 1,94 \\
\hline Cistina & 0,54 & 0,31 & 0,37 & 0,17 & 0,64 & 0,51 & 0,61 & 0,47 \\
\hline Alanina & 3,87 & 3,20 & 3,64 & 2,77 & 4,03 & 3,46 & 3,91 & 3,41 \\
\hline Ácido glutâmico & 6,92 & 5,61 & 6,06 & 4,47 & 7,39 & 6,56 & 7,28 & 6,38 \\
\hline Serina & 2,35 & 1,78 & 1,97 & 1,37 & 2,36 & 1,95 & 2,28 & 1,94 \\
\hline Tirosina & 1,30 & 1,14 & 0,93 & 0,75 & 1,66 & 1,55 & 1,68 & 1,53 \\
\hline
\end{tabular}




\section{Conclusões}

Nas farinhas de vísceras de aves e suínos, os valores de energia metabolizável aparente, aparente corrigida para balanço de nitrogênio, de energia metabolizável verdadeira e verdadeira corrigida são de $2.802 ; 3.018 ; 3.639$ e $3.082 \mathrm{kcal} / \mathrm{kg}$, respectivamente. Os coeficientes de metabolizabilidade da energia metabolizável aparente e aparente corrigida para balanço de nitrogênio e da energia metabolizável verdadeira e verdadeira corrigida para o balanço de nitrogênio variam de 46,13 a 61,96; 51,91 a 67,96; 64,11 a 78,28 e 51,01 a 67,12 . Os coeficientes médios de digestibilidade verdadeira dos aminoácidos essenciais e não-essenciais de farinha de vísceras de aves e suínos são, respectivamente, 81,20 e 74,$55 ; 75,73$ e 67,$15 ; 88,45$ e 85,$20 ; 89,27$ e 84,35 .

\section{Referências}

BELlaVER, C.; BRUM, P.A.R.; LIMA, G.M.M. et al. Substituição parcial do farelo de soja pela farinha de vísceras de aves em dietas balanceadas com base na proteína e em aminoácidos totais ou digestíveis para frangos de corte. Revista Brasileira de Ciência Avícola, v.3, n.3, p.223-240, 2001.

BRUGALLI, I.; ALBINO, L.F.T.; SILVA, D.J. et al. Efeito do tamanho da partícula e do nível de substituição nos valores energéticos da farinha de carne e ossos para pintos de corte. Revista Brasileira de Zootecnia, v.28, n.4, p.753-757, 1999.

BRUMANO, G.; GOMES, P.C.; ROSTAGNO, H.S. et al. Aminoácidos digestíveis verdadeiros dos alimentos protéicos determinados com galos cecectomizados. Revista Brasileira de Zootecnia, v.35, n.6, p.2290-2296, 2006.

D'AGOSTINI, P.; GOMES, P.C.; ALBINO, L.F.T. et al. Valores de composição química e energética de alguns alimentos para aves. Revista Brasileira de Zootecnia, v.33, n.1, p.128-134, 2004.

DALIBARD, P.; PAILLARD, E. Use of the digestible amino acid concept in formulating diets for poultry. Animal Feed Science and Technology, v.53, p.189-204, 1995.

GARCIA, A.R.; BATAL, A.B.; DALE, N.M. A comparison of methods to determine amino acid digestibility of feed ingredients for chickens. Poultry Science, v.86, p.94-101, 2007.

GOMES, F.A.; FASSANI, E.J.; RODRIGUES, P.B. et al. Valores energéticos de alguns alimentos utilizados em rações para codornas japonesas. Revista Brasileira de Zootecnia, v.36, n.2, p.396-402, 2007.

LEESON, S.; SUMMERS, J.D. Scott's nutrition of the chicken. 4.ed. Guelph: University Books, 2001. p.591.

LEMME, A.; RAVINDRAN, V.; BRYDEN, W.L. Ileal digestibility of amino acids in feed ingredients for broilers. World's Poultry Science Journal, v.60, p.423-438, 2004.

MATTERSON, L.D.; POTTER, L.M.; STUTZ, M.W. et al. The metabolizable energy of feed ingredients for chickens. Storrs: The University of Connecticut, Agricultural Experiment Station, 1965. (Research Report, 7).

MELLO, H.H.C.; GOMES, P.C.; ROSTAGNO, H.S. et al. Valores de energia metabolizável de alguns alimentos obtidos com aves de diferentes idades. Revista Brasileira de Zootecnia, v.38, n.5, p.863-868, 2009.

NAJAFABADI, H.J.; MOGHADDAM, H.N.; POURREZA, J. et al. Determination of chemical composition, mineral contents, and protein quality of poultry by-product meal. International Journal of Poultry Science, v.6, n.12, p.875-882, 2007.

NASCIMENTO, A.H. Determinação do valor nutritivo da farinha de vísceras e da farinha de penas para aves, utilizando diferentes metodologias. 2000. 113f. Tese (Doutorado em Zootecnia) - Universidade Federal de Viçosa, Viçosa, MG.

NASCIMENTO, A.H.; GOMES, P.C.; ALBInO, L.F.T. et al. Composição química e valores de energia metabolizável das farinhas de penas e vísceras determinados com diferentes metodologias para aves. Revista Brasileira de Zootecnia, v.31, n.3, p.1409-1417, 2002.

NASCIMENTO, A.H.; GOMES, P.C.; ROSTAGNO, H.S. et al, Valores de energia metabolizável de farinhas de penas e de vísceras determinados com diferentes níveis de inclusão e duas idades das aves. Revista Brasileira de Zootecnia, v.34, n.3, p.877-881, 2005.

NATIONAL RESEARCH COUNCIL - NRC. Nutrient requirements of poultry. 9.ed. Washington, D.C.: National Academy Press, 1994. 155p.

NENGAS, I.; ALEXIS, M.N.; DAVIES, S.J. High inclusion levels of poultry meals and related byproducts in diets for gilthead seabream Sparus aurata L. Aquaculture, v.179, p.13-23, 1999.

NUNES, R.V.; POZZA, P.C.; NUNES, C.G.V. et al. Valores energéticos de suprodutos de origem animal para aves. Revista Brasileira de Zootecnia, v.34, n.4, p.1217-1224, 2005.

NUNES, R.V.; ROSTAGNO, H.S.; GOMES, P.C. et al. Valores energéticos de diferentes alimentos de origem animal para aves. Revista Brasileira de Zootecnia, v.35, n.4, p.1752-1757, 2006.

OST, P.R.; RODRIGUES, P.B.; FREITAS, R.T.F. et al. Aminoácidos digestíveis verdadeiros de alguns alimentos protéicos determinados em galos cecectomizados e por equações de predição. Revista Brasileira de Zootecnia, v.36, n.6, p.1820-1828, 2007.

PARSONS, C.M. Digestible amino acids for poultry and swine. Animal Feed Science Technology, v.59, p.147-153, 1996.

PAULA, A.; BRUM, P.A.R.; AVILA, V.S. et al. Valores de energia metabolizável da farinha de carne e ossos e farinha de vísceras determinados com diferentes níveis de substituição para frangos de corte. Revista Brasileira de Agrociência, v.8, n.1, p.51$55,2002$.

POZZA, P.C.; GOMES, P.C.; DONZELE, J.L. et al. Digestibilidade ileal aparente e verdadeira dos aminoácidos de farinhas de vísceras para suínos. Revista Brasileira de Zootecnia, v.34, n.6, p.2337-2334, 2005.

PUPA, J.M.R.; LEÃO, M.I.; CARVALHO, A.U. et al. Cecectomia em galos sob anestesia local e incisão abdominal. Arquivo Brasileiro de Medicina Veterinária e Zootecnia, v.50, n.5, p.531-535, 1998 .

ROBBINS, D.H.; FIRMAN, J.D. Evaluation of the metabolizable energy of poultry by-product meal for chickens and turkeys by various methods. International Journal of Poultry Science, v.5, n. 8, p.753-758, 2006.

ROSTAGnO, H.S.; ALBINO, L.F.T.; DONZELE J.L. et al. Tabelas brasileiras para aves e suínos: composição de alimentos e exigências nutricionais. Viçosa, MG: UFV, Departamento de Zootecnia, 2005. p.186.

ROSTAGNO, H.S.; FEATHERSTON, W.R. Estudos de métodos para determiner disponibilidade de aminoácidos em pintos. Revista da Sociedade Brasileira de Zootecnia, v.6, n.1, p.64-76, 1977.

SANTOS, Z.A.S.; FREITAS, R.T.F.; FIALHO, E.T. et al. Valor nutricional de alimentos para suínos determinado na Universidade Federal de Lavras. Ciência Agrotécnica, v.29, n.1, p.232-237, 2005.

SHIRLEY, R.B.; PARSONS, C.M. Effect of ash content on protein quality of meat and bone meal. Poultry Science, v.80, p.626-632, 2001. 
SIBBALD, I.R. A bioassay for available amino acids and true metabolizable energy in feedstuffs. Poultry Science, v.55, p.303-308, 1976.

SILVA, D.J.; QUEIROZ, A.C. Análise de alimentos (métodos químicos e biológicos). 1. reimpressão. Viçosa, MG: Editora UFV, 2002. 235p.

TUCCI, F.M.; LAURENTIZ, A.C.; SANTOS, E.A. et al. Determinação da composição química e dos valores energéticos de alguns alimentos para aves. Acta Scientiarum, v.25, n.1, p.85-89, 2003.
UNIVERSIDADE FEDERAL DE VICOSA - UFV. Manual de utilização do programa SAEG (Sistema para Análise Estatísticas e Genéticas). Viçosa, MG, 1999. 59p.

VIEITES, F.M.; ALBINO, L.F.T.; SOARES, P.R. et al. Valores de energia metabolizável aparente da farinha de carne e ossos para aves. Revista Brasileira de Zootecnia, v.29, n.6, p.2292-2299, 2000.

ZANOTTO, D.L.; BELlAVER, C. Método de determinação da granulometria de ingredientes para uso em rações de suínos e aves. Concórdia: Embrapa Suínos e Aves, 1996. p.1-5. (Comunicado Técnico). 